\title{
Development of functional caramel using system packages MathLab
}

\author{
Nikolay Nikolaevich Berezhnov ${ }^{1, *}$, Marina Gennadievna Kurbanova ${ }^{2}$, and Anastasia \\ Yurievna Kolbina ${ }^{1}$ \\ ${ }^{1}$ FSBEI HE Kuzbass State Agricultural Academy, 650056, st. Markovtseva, 5, Kemerovo, Russia \\ ${ }^{2}$ FSBEI HE "Kemerovo State University" (KemSU), 650000, st. Krasnaya, 6, Kemerovo, Russia
}

\begin{abstract}
The article presents substantiation for expanding the market for functional food products, in particular, confectionery - caramel. Proper nutrition is an integral part of a modern person diet; due to their properties, they increase the immunity and immune status of a person. The aim of the work is to create composite mixtures for sugar-free caramel using modern software. The studies were carried out using the MathLab software package, in particular the Statistica 10.0 software. A methodology for creating recipes using system packages has been developed. To enrich the caramel, the following components were selected: apple juice, coltsfoot extract, orange juice, mint and burdock extract, cranberry and lingonberry juices. An optimal recipe has been designed and equations are presented for calculating the dosages of the components of the enriched sugar-free caramel based on a natural sweetener isomalt with the addition of plantbased additives containing macro and micronutrients necessary for the normal functioning of the human body with a diagnosis of type II diabetes mellitus.
\end{abstract}

\section{Introduction}

In recent decades, consumer demand for healthy foods such as re-formulated foods (such as low-fat or fiber-added foods) and functional foods has grown rapidly. Consumer demand has risen in part due to socio-economic changes such as increased life expectancy, rising health care costs, the social costs associated with non-communicable diseases, and widespread desire for a better quality of life. According to experts, the world market for food products with functional action in 2020 is $\$ 168$ billion with an average annual growth rate of $8.5 \%$ [1, p. 142]. Food companies, attracted by this market growth and high profitability, are investing in the development of new functional products.

In recent decades, consumer demand for healthy food products such as re-formulated food (such as low-fat or fiber-added) and functional food has grown rapidly. Consumer demand has risen in part due to some socio-economic changes as increased life expectancy, rising health care costs, the social costs associated with non-communicable diseases, and widespread desire for a better quality of life. According to experts, in 2020 the world market of food products with functional properties is $\$ 168$ billion with an average annual

\footnotetext{
* Corresponding author: n.berezhnov@mail.ru
} 
growth rate of $8.5 \%$ [1, p.142]. Food producing companies, attracted by this market growth and high profitability, are investing in the development of new functional products.

Functional food play an important role in the development and expansion of the food market. This is mentioned, in particular, in the presidential decree of January 30, 2010 "On the adoption of the Food Security Doctrine of the Russian Federation" and the Order of the Government of the Russian Federation of June 29, 2016 No. 1364-r "On the approval of the strategy for improving the quality of food products of the Russian Federation to 2030 "[2, p.113].

The main principle of developing functional products is to expand the range of traditional products by adding enriching components on natural basis to their composition.

Eating habits acquired in childhood affect a person's lifestyle and behavioral changes [7, p. 110]. Insufficient intake of macro- and micronutrients caused by improper diet is the cause of the development of diseases associated with the immune system. In addition, lack of knowledge about healthy food raion among young people and children also leads to unhealthy eating habits that negatively affect their health [8, p.169].

Type II diabetes mellitus is one of the most common diseases of the 21 st century. According to research by scientists, in 2019 there were about 285 million patients all over the world (6.4\% of the world's adult population), and by 2020 this number had increased to 438 million (7.8\% of adults) [9, p. 105]. Over the past decades, the prevalence of diabetes has increased especially in countries with low and middle living standards. According to experts, diabetes mellitus is the 9th and 21 st cause of death in the third world countries among men and women, respectively [9, p.105]. Lifestyle modification, including weight management, physical activity and diet, plays an important role in reducing the prevalence of type II diabetes mellitus [10, p. 736].

In Russia, to control the number of cases, a special website was created for monitoring and helping patients - www.diaregistry.ru, it contains all the relevant information. So, according to the site, as of June 1, 2020, the number of registered cases is 4,833,923 people, of which the increase in the number of cases for the year was 169,451 people. At the same time, it is worth noting that patients with type II diabetes mellitus make up $92.5 \%$ of the total number, and $90.5 \%$ of the number of patients with diabetes since the beginning of 2020 .

When suffering from type II diabetes mellitus, a person should exclude sucrose containing food from the diet. To restrain from eating products with a large amount of sugar, e.g. confectionery, is also preferable for people who monitor their health and go in for sports [3, p.10, 4, p.6]. Nevertheless, an analysis of the Russian market for specialized food products revealed a deficit in the assortment of confectionery products for these groups of population.

Also, in the diet of diabetics, it is necessary to include foods containing inulin - a natural analogue of insulin, which is found in large quantities in burdock (57\%), foalfoot, garlic, Jerusalem artichoke, chicory and other plant species. According to scientists, the inulin contained in burdock is better absorbed and has a greater positive effect on the human body than other types of plant materials [6, p.355].

When developing any recipes, it is also relevant to take into account the consumers' taste preferences. Thus, according to the results of research of the Research Institute of Nutrition of the Russian Academy of Medical Sciences, the clinic of the Federal State Budgetary Institution "Federal Research Center of Nutrition and Biotechnology", the taste preferences of patients with diabetes mellitus were determined, which are recommended for consideration when developing a line of specialized confectionery products, these are orange, green apple, mint, vanilla, peach, lingonberry, cranberries, blackberries [5, p.140].

Purpose of the study is creation of composite mixtures for sugar-free caramel using modern software. 


\section{Materials and Methods}

The studies were carried out using the MathLab software package, in particular the software Statistica 10.0.

\section{Results and Discussions}

In the course of the research, based on the scores of organoleptic quality indicators, there were determined the maximum allowable dosages of fortifying additives. On their basis, regression dependences have been obtained, which make it possible to determine with a high degree of reliability the optimal dosages for obtaining a product with high organoleptic properties. Orange juice, mint extract and burdock extract were chosen as the main enrichment additives. The choice of the components was made due to their chemical composition, as well as the recommendations of dietitians. In addition, the bulk of the components used is got from the raw materials growing on the territory of Kuzbass and as a result it is readily available.

The task of the study was to determine the dosage of the component mixture by the method of mathematical modeling. For this, we used the data obtained from the control group of subjects based on the results of evaluating the product organoleptic properties. The analysis of consumer preferences of the target audience was carried out by the method of a sociological survey using a questionnaire based on quota samples, taking into account gender, age and educational level of the composition of the control group of consumers. According to the results of the survey, the respondents were given a point score, which serves as a comprehensive assessment criterion for the organoleptic properties of the product.

The factors influencing the receipt of high score organoleptic assessment of quality indicators are presented in table 1 .

Table 1. Factors and levels of their variation.

\begin{tabular}{|c|c|c|c|c|c|c|c|}
\hline Designations & $\begin{array}{l}\text { Apple } \\
\text { juice, } \\
\mathrm{cm}^{3} / \mathrm{kg}\end{array}$ & $\begin{array}{l}\text { Extract } \\
\text { of } \\
\text { foalfoot, } \\
\mathrm{cm}^{3} / \mathrm{kg}\end{array}$ & $\begin{array}{l}\text { Cranberry } \\
\text { juice, } \\
\mathrm{cm}^{3} / \mathrm{kg}\end{array}$ & $\begin{array}{l}\text { Orange } \\
\text { juice, } \\
\mathrm{cm}^{3} / \mathrm{kg}\end{array}$ & $\begin{array}{c}\text { Lingonberry } \\
\text { juice, } \\
\mathrm{cm}^{3} / \mathrm{kg}\end{array}$ & $\begin{array}{c}\text { Burdock } \\
\text { extract, } \\
\mathrm{cm}^{3} / \mathrm{kg}\end{array}$ & $\begin{array}{l}\text { Mint } \\
\text { extract, } \\
\mathrm{cm}^{3} / \mathrm{kg}\end{array}$ \\
\hline & $\mathrm{X}_{1}$ & $\mathrm{X}_{2}$ & $\mathrm{X}_{3}$ & $\mathrm{X}_{4}$ & $\mathrm{X}_{5}$ & $\mathrm{X}_{6}$ & $\mathrm{X}_{7}$ \\
\hline $\begin{array}{c}\text { Upper level } \\
(+)\end{array}$ & 7,0 & 4,0 & 7,0 & 6,0 & 7,0 & 5,0 & 1,0 \\
\hline $\begin{array}{c}\text { Main level } \\
(0)\end{array}$ & 5,0 & 3,0 & 5,0 & 5,0 & 5,0 & 4,0 & 0,5 \\
\hline $\begin{array}{c}\text { Lower level } \\
(-)\end{array}$ & 4,0 & 2,0 & 4,0 & 4,0 & 4,0 & 2,0 & 0,3 \\
\hline
\end{tabular}

Implementation of the experiment on the design matrix, presented in Table 1, made it possible to obtain the values of the optimization criteria and mathematical models in the form of a regression equation.

The results are shown in Table 2. 
Table 2. The results of the organoleptic score assessment of the product.

\begin{tabular}{|c|c|c|c|c|c|c|c|c|c|c|}
\hline \multirow{2}{*}{ Experiment No. } & \multicolumn{7}{|c|}{ Mixture components (X factors) } & Organoleptic score (response Y) \\
\cline { 2 - 7 } & $\mathrm{X}_{1}$ & $\mathrm{X}_{2}$ & $\mathrm{X}_{3}$ & $\mathrm{X}_{4}$ & $\mathrm{X}_{5}$ & $\mathrm{X}_{6}$ & $\mathrm{X}_{7}$ & \\
\hline \multicolumn{8}{|c|}{} \\
\hline 1 & 4 & 2 & - & - & - & 5 & - & 27,5 \\
\hline 2 & 4 & 4 & - & - & - & 2 & - & 26,8 \\
\hline 3 & 7 & 2 & - & - & - & 2 & - & 28,3 \\
\hline 4 & 5 & 3 & - & - & - & 4 & - & 27,6 \\
\hline \multicolumn{8}{|c|}{ Mixture №2 } \\
\hline 5 & - & - & 4 & - & 7 & 2 & - & 28,4 \\
\hline 6 & - & - & 4 & - & 4 & 5 & - & 26,9 \\
\hline 7 & - & - & 7 & - & 4 & 2 & - & 29,1 \\
\hline 8 & - & - & 5 & - & 5 & 4 & - & 29,1 \\
\hline \multicolumn{7}{|c|}{ Mixture №3 } \\
\hline 9 & - & - & - & 6 & - & 2 & 0,3 & 29,8 \\
\hline 10 & - & - & - & 4 & - & 2 & 1 & 28,6 \\
\hline 11 & - & - & - & 4 & - & 5 & 0,3 & 27,4 \\
\hline 12 & - & - & - & 5 & - & 4 & 0,5 & 28,9 \\
\hline
\end{tabular}

The processing of experimental data in the study was carried out by statistical methods of analysis using the applied programs "Statistica" and "Microsoft Excel". The adequacy of the obtained regression equations was assessed using Fisher's criterion according to the condition $\mathrm{F}_{\mathrm{R}}>\mathrm{F}_{\mathrm{Ti}}$. To obtain reliable results, the required number of experiments was calculated. In the experiments, three parallel determinations were reproduced in four replicates. The numerical values that are presented in tables and graphs reflect the arithmetic mean, with a confidence level of $\mathrm{P}=0.95$ and a confidence interval of $\pm 10 \%$.

Based on the experiments carried out, screening out statistically insignificant coefficients, using the stepwise regression method, after appropriate mathematical processing, the following equations were obtained:

- mixture №1

$$
\begin{gathered}
Y=25,667+0,389 x_{1}-0,167 x_{2}+1,236 x_{1} x_{2}+0,815 x_{1} x_{6}+0,122 x_{2} x_{6} \\
-1,318 x_{1}^{2}+0,935 x_{2}^{2}+1,241 x_{6}^{2} \\
R=0,832, F=1,054
\end{gathered}
$$

- mixture №2

$$
\begin{gathered}
Y=18,143+0,729 x_{3}-1,467 x_{5}+1,231 x_{3} x_{5}+0,709 x_{5} x_{6}+0,0048 x_{3} x_{6} \\
+0,802 x_{3}^{2}-1,012 x_{5}^{2}+0,357 x_{6}^{2} \\
R=0,826, F=2,676
\end{gathered}
$$

- mixture №3

$$
\begin{gathered}
Y=26,702+0,636 x_{4}-0,376 x_{6}+0,104 x_{4} x_{6}+1,111 x_{4} x_{7}+1,41 x_{4}^{2} \\
-0,415 x_{6}^{2}-1,115 x_{6}^{2} \\
R=0,802, F=1,425
\end{gathered}
$$


A graphical interpretation of the dependence of the organoleptic parameters of candy caramel enriched with extracts on their quantitative ratio is presented in Figures 1-3.


Fig. 1. Surface response (mixture 1) $\mathrm{Y}=\mathrm{f}(\mathrm{X} 1, \mathrm{X} 2, \mathrm{X} 6=4,0)$. 

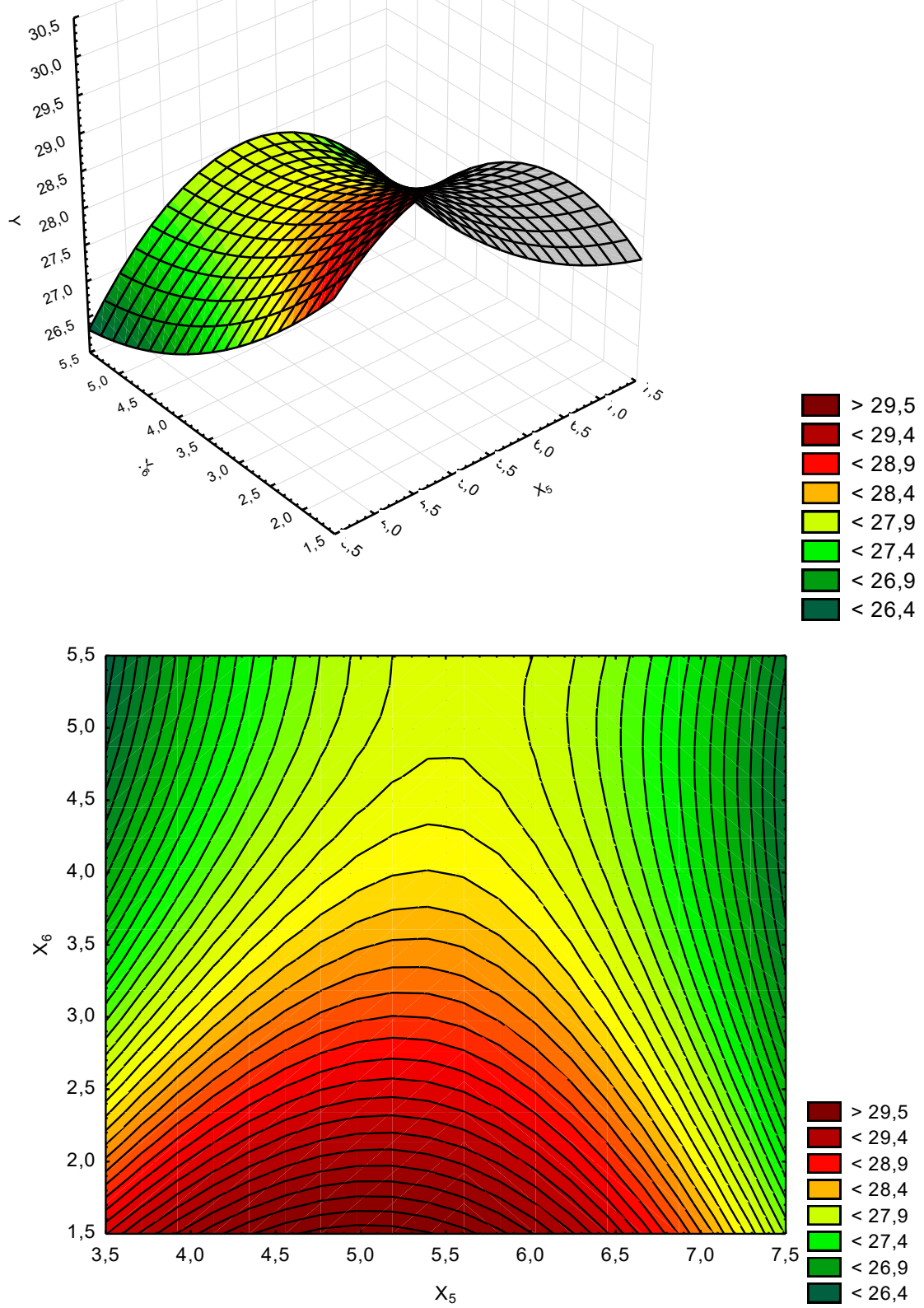

Fig. 2. Surface response (mixture 2) $Y=f(X 5, X 6, X 3=5,0)$. 

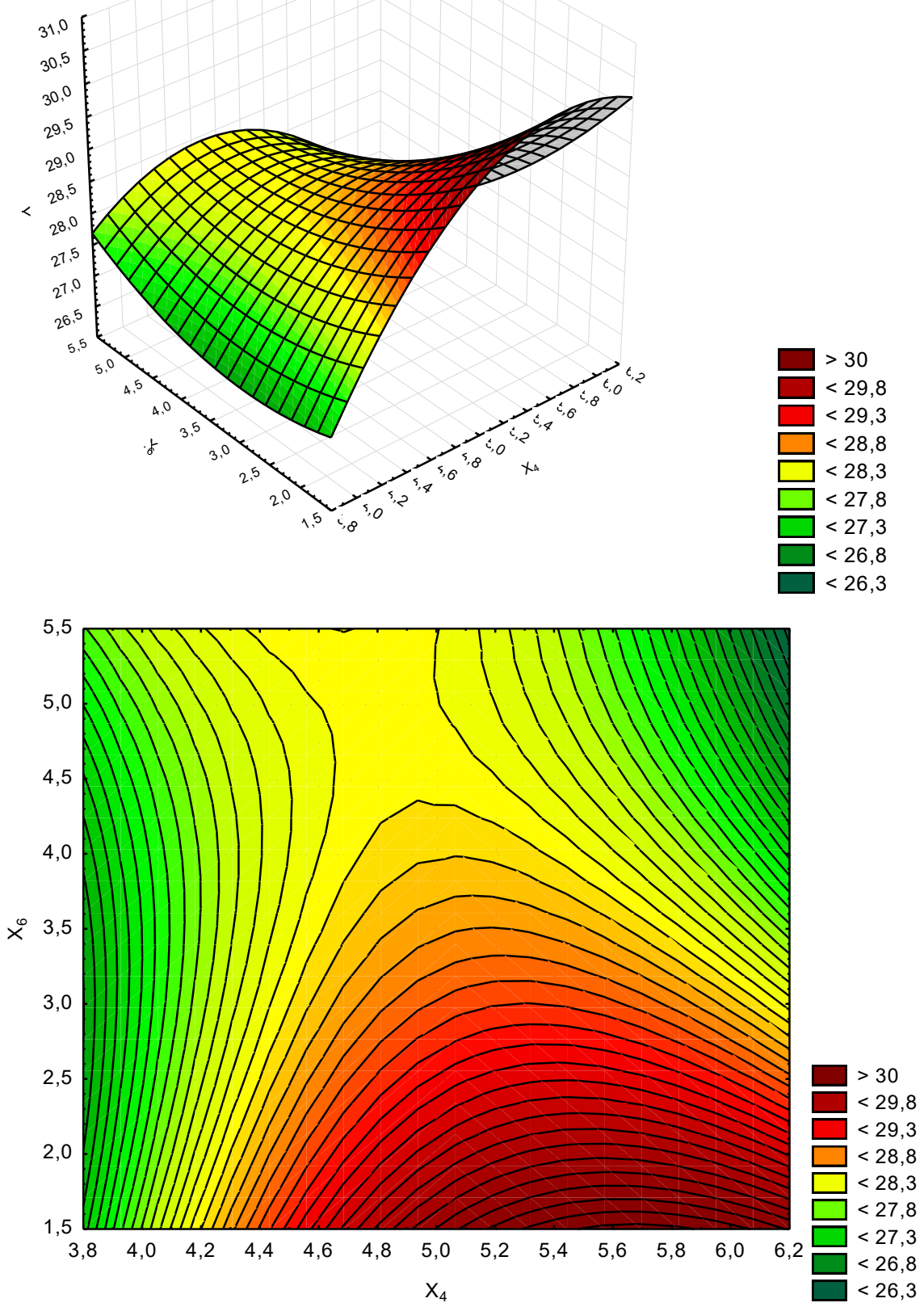

Fig. 3. Surface response (mixture 3) $\mathrm{Y}=\mathrm{f}(\mathrm{X} 4, \mathrm{X} 6, \mathrm{X} 7=0,5)$.

Thus, the conducted studies allow concluding that the following ratio of extracts is a more accurate ratio of extracts to obtain enriched caramel with high organoleptic characteristics (table 3). 
Table 3. Ratios of enriching extracts (in shares)

\begin{tabular}{|c|c|c|c|c|c|c|c|}
\hline Designations & $\begin{array}{c}\text { Apple } \\
\text { juice, } \\
\mathrm{cm}^{3} / \mathrm{kg}\end{array}$ & $\begin{array}{c}\text { Extract } \\
\text { of } \\
\text { foalfoot, } \\
\mathrm{cm}^{3} / \mathrm{kg}\end{array}$ & $\begin{array}{c}\text { Cranberry } \\
\text { juice, } \\
\mathrm{cm}^{3} / \mathrm{kg}\end{array}$ & $\begin{array}{c}\text { Orange } \\
\text { juice, } \\
\mathrm{cm}^{3} / \mathrm{kg}\end{array}$ & $\begin{array}{c}\text { Lingonberry } \\
\text { juice, } \mathrm{cm}^{3} / \mathrm{kg}\end{array}$ & $\begin{array}{c}\text { Burdock } \\
\text { extract, } \\
\mathrm{cm}^{3} / \mathrm{kg}\end{array}$ & $\begin{array}{c}\text { Mint } \\
\text { extract, } \\
\mathrm{cm}^{3} / \mathrm{kg}\end{array}$ \\
\hline $\mathrm{X}_{1}$ & $\mathrm{X}_{2}$ & $\mathrm{X}_{3}$ & $\mathrm{X}_{4}$ & $\mathrm{X}_{5}$ & $\mathrm{X}_{6}$ & $\mathrm{X}_{7}$ \\
\hline mixture №1 & 0,39 & 0,94 & - & - & - & 0,12 & - \\
\hline mixture №2 & - & - & 0,73 & - & 0,71 & 0,35 & - \\
\hline mixture №3 & - & - & - & 0,64 & - & 0,42 & 0,05 \\
\hline
\end{tabular}

Therefore, the recipe for the enriched caramel will be as shown in table 4.

Table 4. Enriched caramel recipe

\begin{tabular}{|c|c|c|c|c|c|c|c|}
\hline Designations & $\begin{array}{c}\text { Apple } \\
\text { juice, } \\
\mathrm{cm}^{3} / \mathrm{kg}\end{array}$ & $\begin{array}{c}\text { Extract } \\
\text { of } \\
\text { foalfoot, } \\
\mathrm{cm}^{3} / \mathrm{kg}\end{array}$ & $\begin{array}{c}\text { Cranberry } \\
\text { juice, } \\
\mathrm{cm}^{3} / \mathrm{kg}\end{array}$ & $\begin{array}{c}\text { Orange } \\
\text { juice, } \\
\mathrm{cm}^{3} / \mathrm{kg}\end{array}$ & $\begin{array}{c}\text { Lingonberry } \\
\text { juice, } \mathrm{cm}^{3} / \mathrm{kg}\end{array}$ & $\begin{array}{c}\text { Burdock } \\
\text { extract, } \\
\mathrm{cm}^{3} / \mathrm{kg}\end{array}$ & $\begin{array}{c}\text { Mint } \\
\text { extract, } \\
\mathrm{cm}^{3} / \mathrm{kg}\end{array}$ \\
\hline mixture №1 & 42 & 53 & - & - & - & 10 & - \\
\hline mixture №2 & - & - & 64 & - & 48 & 7 & - \\
\hline mixture №3 & - & - & - & 82 & - & 9 & 3 \\
\hline
\end{tabular}

\section{Conclusions}

Based on the results of calculating the recipes and using programs for analysis, the optimal dosages of enriching additives for creating candy caramel for diabetic nutrition have been determined. According to the revealed regression equations, the calculation method can be used to determine the amount of added additives, depending on the mass of the required finished products.

\section{References}

1. N. Aktaş, Y. Özdoğan, Reserachers World, 7, 46 (2016)

2. F. Bimbo, A. Bonanno, G. Nocella, R. Viscecchia, G. Nardone, B. De Devitiis, D. Carlucci, Appetite, 113, 141 (2017)

3. S. Emami et al., International Journal of Preventive Medicine, 10 (2019)

4. S. Firouzi, M. Y. Barakatun-Nisak, K. N. Azmi, J Res Med Sci., 20, 40 (2015)

5. L. Guariguata, D. R. Whiting, I. Hambleton, J. Beagley, U. L. Linnenkamp, J. E. Shaw, Diabetes research and clinical practice, 103, 137 (2014)

6. I. Kalkan, Nutrition research and practice, 13(4), 352 (2019)

7. I. I. Dedov, M. V. Shestakova, G. R. Galstyan, Diabetes Mellitus, 19, 104 (2016)

8. A. Yu. Kolbina, M. G. Kurbanova, Agroindustrial complex - new ideas and solutions, 168 (2020)

9. G. G. Oganesyan, A. V. Topchyan, A. A. Barsegyan, L. V. Revazova, N. G. Grigoryan, R. M. Bagumyan, Bulletin of the Medical Institute, 2, 103 (2006)

10. E. V. Smirnov, Food flavorings. Directory, 736 (2008) 